\title{
Archiving and Document Management at Taibah University: A Case Study
}

\author{
Jamilah Alokluk $^{1}$ \\ ${ }^{1}$ College of Arts and Humanities, Taibah University, Madinah, Saudi Arabia \\ Correspondence: Dr. Jamilah Alokluk, College of Arts and Humanities, Taibah University, Madinah, Saudi \\ Arabia.
}

Received: August 8, 2019

Accepted: August 28, 2019

Online Published: September 24, 2019

doi:10.5539/cis.v12n4p11

URL: https://doi.org/10.5539/cis.v12n4p11

\begin{abstract}
Archiving and digital document management in educational institutions are not amply studied despite the active use of technologies for these purposes. In this research, a qualitative descriptive case study has been conducted to examine how digital archiving and document management are organised at Taibah University to address the needs of researchers, professors, administrators and students as well as to guarantee secure storage of and access to data. The selection of the case study design has allowed for in-depth analyses of the strategy for managing and archiving data in the selected institution. The interpretation of data with reference to the previously formulated propositions have indicated that Taibah University follows a certain strategy for managing electronic documents, but they do not use a unique data management system. Furthermore, archiving is applied only to a limited number of documents and security of stored data is guaranteed according to the University's policies.
\end{abstract}

Keywords: archiving, data management, digital document management, document management, security

\section{Introduction}

Today, educational institutions face the challenge of coping with large volumes of information presented as printed or paper-based and electronic data. Traditional archives adopted for depositing printed documents have been replaced recently with digital archival and data management systems to organise and store all the possible information collected and used in universities and colleges. In educational institutions, the use of information management systems is grounded in the need to design, collect, store, categorise, and expand data handled by organisations for their daily activities (Maican \& Lixandroiu 2016). Typically, educational institutions collect and preserve documents and records related to research and scientific activities, educators, students, courses, curricula, scholarships and internships, as well as tuition fees among other categories.

Currently, colleges and universities need to keep and maintain a lot of data, and they express a considerable demand for using the most appropriate tools and approaches to managing their information and documents. The purpose of digital archiving and electronic data management in this context is to improve administrators', academics', and researchers' daily activities to contribute to the achievement of their specific goals. Higher educational institutions depend on the effective document management and archiving because they regularly utilise course and teaching materials, publications, theses and dissertations, manuscripts, students' application forms, records, submissions, reports, regulations, and policies, as well as administrative files, video and audio files (Maican \& Lixandroiu 2016; Van Loon et al. 2017). As a result, administrators and managers, as well as academics and researchers, working in educational institutions are interested in following policies and using systems that ensure the efficient management and storage of documents and other types of data. The application of an effective digital archiving system allows for easy vertical and horizontal flows of information in an organisation.

The problem identified above in regards to data management is that incoming and internal documents and records, as well as data related to studies and publications, need to be not only available to stakeholders but also stored securely for as long time as possible. Information technologies along with clouding and web resources provide administrators with a range of opportunities to choose the most effective approaches and tools to be applied in their organisations for archiving and managing different volumes of data (Srivastava \& Misra, 2017). Digital resources are selected because they allow for avoiding constraints associated with the limited space for archives typical of paper-based documents and systems (Cristani et al., 2018; Maican \& Lixandroiu, 2016). 
Nevertheless, in spite of obvious advantages of using electronic management systems for working with digital data in educational institutions, there is also an issue of security in order to guarantee that all data entered into an organisational system are protected and cannot be easily disclosed to a third party.

In addition to the evident issue of security of digital data, there are also other problems to pay attention to when discussing the question of data management in educational institutions. They include the absence of a single responsibility for managing information, the use of inconsistent archiving resources, the underdeveloped data management function, the lack of cohesion in the used system, and the lack of users' skills to work with data archives (Joshi \& Singh 2017; Van Loon et al. 2017). From this perspective, the research problem to be studied in the context of this project is associated with the issues of managing digital sources effectively and securely, depending on the demand of a higher educational institution. This research problem provides the grounds for the current project, the aim of which is to determine how universities can address the archiving and document management question in the most effective manner to respond to the interests of stakeholders.

The available literature on the problem of digital archiving and information in educational institutions does not provide specific answers to the inquiries regarding the experiences of particular institutions in the sphere of higher education. As a result, the research interest realised in this study is associated with the necessity of examining how data management is organised in such an institution as Taibah University located in Madinah, Saudi Arabia. Therefore, the following research question is aimed to be answered in this research paper:

RQ: How are digital archiving and document management organised at Taibah University to address the needs of researchers, professors, administrators and students as well as to guarantee the secure storage of and access to data?

The collection and analysis of data related to this qualitative research based on the case study will contribute to other researchers' understanding of the experience UK universities have in applying different approaches to information management in their organisations. The remainder of this paper will present the review of the literature available on the studied topic, the analysis of data collected for the selected case study, and discussions and conclusions associated with interpreting how the formulated propositions are reflected or not in the research. Thus, the following propositions guide this research: a) Taibah University has a modern complex system of electronic data management addressing stakeholders' needs; b) the University provides an effective system for archiving electronic documents; c) the data management system implemented at the University guarantees the secure storage of and access to data.

\section{Review of Literature}

Researchers have studied digital archiving and document management in different types of organisations from a variety of perspectives, and their conclusions need to be reviewed there to provide the background for the current study. The discussion of other researchers' findings connected with the topic of this study is presented in detail. In addition, it is also necessary to discuss the theoretical framework for this research in order to provide the context for explaining administrators' and managers' choices regarding data management from the theoretical perspective.

\section{Theoretical Framework}

Information technologies and systems used for storing and managing data provide organisations with opportunities to perform regular tasks effectively, have constant access to required data, and organise the work with materials efficiently. The theory that allows for explaining how information technologies can add to improving organisational performance in terms of data management among other aspect is known as the task-technology fit (TTF) model. This theory was firstly proposed and developed by Dale L. Goodhue and Ronald L.Thompson in order to explain how technology can assist people with reference to its potential positive impact on individuals' operations and task performance (Howard \& Rose 2018). Thus, the core goal of the theory is to describe a specific fit between the nature of a certain task and the selected technology to use. Thus, technologies, in the form of computers, clouds, web resources, web storage spaces, hardware, and software are discussed as particular tools that are used by people in order to perform their duties and complete a range of tasks.

According to the principles of the TTF model, technologies are applied to improve individuals' activities and performance, to simply and optimise them. Therefore, the authors of this theory accentuated the necessity of adopting only those technologies that can mostly contribute to performing jobs effectively. If there is not a proper fit between the task and the technology to complete it, it is almost impossible to achieve a positive result and improve individuals' performance in this selected area of activities (Wu \& Chen 2017). The TTF model was 
applied and analysed in the studies by Wu and Chen (2017) and Howard and Rose (2018) in order to support the analysis of how the application of certain tools and systems can contribute to processing data in educational institutions.

\section{Document Management in Educational Institutions}

The review of recent studies published on the problem of data management in colleges and universities has revealed the lack of research related to this topic in spite of the fact that educational institutions, as any other organisations, need to manage large volumes of data on a daily basis. Researchers discussed different variants of organising data storage in various organisations with reference to assessing the effectiveness of managing digital documents with the help of certain electronic management systems (Sabireen, Kirthica \& Sridhar 2017; Srivastava \& Misra 2017). According to Srivastava and Misra (2017), data management is often a costly process that makes managers and administrators choose unique tools and software for decreasing the volume of managed data, creating efficient databases, and reducing data for archiving. Therefore, administrators are often interested in selecting cost-efficient data management systems to address organisational needs.

While selecting hardware or software to save data securely for a long period of time, it is important to pay attention to the fact that technologies quickly become outdated, and it can be difficult to retrieve the stored material and files in several years. Databases used for data management should work efficiently according to policies that guarantee the security of data (Maican \& Lixandroiu 2016). In addition to typical digital data management systems, it is also necessary to use databases for archiving documents. All these databases need to have an effective system for updating, accessing, changing, and deleting data that are available from archives and repositories (Maican \& Lixandroiu 2016; Van Loon et al. 2017). Furthermore, document management in organisations should also be associated with creating database backups to guarantee access to data online and offline, using various storages.

Not many researchers studied data management systems and the effectiveness of their implementation in educational institutions. Discussing the specifics of implementing an open source enterprise content management system in a Romanian university, Maican and Lixandroiu (2016) focused on the analysis of other models applied by educational institutions. Different types of organisations integrate management information systems, enterprise resource planning, decision support systems, and knowledge management systems in order to manage various categories of data and guarantee their flow in an organisation (Maican \& Lixandroiu 2016). All these systems can be effectively used for managing incoming and outgoing documents, as well as secure internal documents, and administrators choose the system depending on their organisation's specific needs.

Those researchers who focused on discussing data management in educational institutions agreed that many colleges and universities usually select data management systems and tools referring not only to proposed functions but also to costs. The reason is that the storage of large volumes of data can be overpriced, and administrators are interested in minimising data stored or archived in organisations' repositories (Maican \& Lixandroiu 2016; Soomro, Shah \& Ahmed 2016). Additionally, data management systems need to be appropriate for effective and quick data processing, referring to such steps as the transformation of printed documents into digital files, the categorisation of documents, and the organisation of data in files and folders on special drives.

\section{Archiving Data}

Modern organisations need to operate large volumes of data, and in most cases, this information needs to be preserved for further access and use. Digital archiving allows for keeping electronic data in a specific storage space for a long time in order to avoid situations when large database sizes prevent the speedy work of organisations' data management systems. Following Sabireen, Kirthica, and Sridhar (2017, p. 140), "Archive infrastructure must support high volumes of data at low cost, extended data retention and periodic high volume searching." The accumulation of data does not allow data management systems to operate effectively, and some information can be damaged or it cannot be easily retrieved (Joshi \& Singh 2017). In this context, archiving means moving data that are not actively used now from the primary active system to other available storage spaces, including drives, servers, and clouds.

Management of data with the help of archiving is associated with focusing on such important aspects as the availability and size of data repositories, the issue of data integrity, the issue of recovery management, specifics of not only storing but also retrieving information. As it is noted by Srivastava and Misra (2017), educational institutions often face the necessity of archiving their documents using software and the near-line storage as well as cloud storage resources. These steps allow for reducing the sizes of used databases, preserving all required data, and securing information. Any types of third-party platforms used for storing digital data are associated with a lot of issues for universities which use them because of the possible utilisation of non-standardised 
formats and questionable security of the stored data.

Researchers also pay attention to examining the advantages and disadvantages of cloud archiving as a new approach to the prolonged storage of data without risks of damaging files. According to Cristani et al. (2018, p. 74), "cloud archiving is anyhow ubiquitous, so that it makes sense to process the document in situ rather than transferring it from one side to the other one." Still, other researchers support the use of cloud archiving and similar strategies for collected large amounts of data because these systems allow for an easy retrieval of required data (Joshi \& Singh 2017). When documents are not used or required for a long period of time, it is rather simple to delete the archival data. However, according to Sabireen, Kirthica, and Sridhar (2017), cloud storages for data can also be discussed as risky for companies because of the data security issue. Researchers have no single opinion regarding the appropriateness of using cloud computing and archiving large amounts of sensitive data.

A range of studies published during recent years presents the analysis of using archiving for research activities and in relation to scholarly journals and their archives. Koopman and De Jager (2016) and Renaut et al. (2018) concentrated on studying the approaches to archiving digital research-related data, and they found that many researchers do not use proposed repositories for archiving their materials, and moreover, many educational institutions have no effective research data management systems. As a result, there is a risk that, in many cases, documents and research-related data are stored and managed inappropriately, without being accurately and securely archived. In this case, the authors of the studies discussed the problem of archiving from the perspectives of both research and educational initiations and academic journals.

\section{Data Management and Security}

Security of collected and stored data in educational institutions, as well as other types of organisations, is discussed by researchers as a serious issue and a challenge to respond to. The reason is that the security of archived data is the aim for administrators who work with business-related confidential and sensitive data (Joshi \& Singh 2017; Soomro, Shah \& Ahmed 2016). According to Sabireen, Kirthica, and Sridhar (2017), when archiving data using cloud-based systems, it is possible to guarantee security with the help of homomorphic encryption. This technology is viewed as addressing administrators' needs and interests when it is necessary to protect increasing volumes of data using web-based services and software. Thus, there are many different technological solutions that are discussed in the literature as potentially effective or ineffective in order to guarantee the protection of data for organisations (Maican \& Lixandroiu 2016; Soomro, Shah \& Ahmed 2016). The success in protecting data depends on the followed information security policies and specific organisational strategies that regulate employees' access to different types of corporate data.

A variety of factors can have an impact on the realisation of security principles in relation to data management in any organisation. While discussing this issue in their research, Soomro, Shah and Ahmed (2016, p. 218) paid attention to the fact that "organisational factors such as industry type, organisation size and structure strongly influence the implementation of information security management." Thus, the size and industry of an organisation determine what type of data security management should be selected because requirements for security of data in financial organisations and educational institutions are different. The goal of any organisation is to make sure that all the data used for daily corporate activities cannot be accessed by unauthorised users (Sabireen, Kirthica \& Sridhar 2017; Srivastava \& Misra 2017). If a company utilises cloud-based services for document management or unsecured resources and databases for storing and sharing data, there are risks of disclosing important information to the third party, affecting the reputation and performance of an organisation. Therefore, much attention is paid to developing effective security strategies and policies within organisations as well as to implementing efficient information management systems.

\section{Methods}

A qualitative methodology has been selected for this research in order to investigate how higher educational organisations can organise, archive and manage their data with the help of modern technologies. In contrast to a quantitative methodology, this method allows for focusing on details that are important for understanding the administrators' choice (Yin 2017). Furthermore, a case study has been selected as a type of research to refer to the example of a specific institution and experiences of its stakeholders. The selected setting for this research is Taibah University that is located in Taibah, Saudi Arabia. This institution is chosen because it is known as a reputable research university, and it has the tradition of collecting and storing large volumes of research-, curricula-, and student-related data. In spite of being one of the most significant ancient universities in the United Kingdom, Taibah University is famous for applying the latest information technologies in order to address the needs of its academicians and students.

For the purpose of this research, a descriptive case study has been developed in order to describe and analyse 
digital archiving and document management in the context of Taibah University in terms of addressing security issues. A descriptive type of a case study is selected when it is necessary to examine the phenomenon in a specific concept without focusing on relationships or exploring interventions (Yin 2017). The data collection approach that is appropriate for this type of a case study is associated with retrieving the available documentation and records regarding the policies and procedures applied at Taibah University to store and archive different types of information. This data collection approach is used in the context of the qualitative methodology chosen for this study in order to focus on describing how Taibah University organised the management of data and archiving in order to address stakeholders' interests and needs. In this project, the available information on data storage services, the use of drives, the principles of archiving, and management of research data has been collected for further analysis to address the set research question.

The collected data have been analysed with the help of interpreting and linking information to the previously formulated propositions. This technique is actively used by researchers conducting case studies because they usually formulate specific or preconceived ideas before starting their research in order to guide their work (Yin 2017). The analysis of collected data is organised with a focus on the theoretical propositions developed for this study to find the answers to the set research question. Thus, a researcher concentrates on the bias-free analysis and interpretation of only those data that can be used in order to provide a response to the research question. The results of data analysis related to this case study are presented in the following section.

\section{Results}

The analysis of documentation related to the data management activities by Taibah University has indicated that the University promotes the use of a centrally managed storage for accumulating and archiving all digital data related to research, teaching, and administration activities of researchers, educators, students, and administrators. The principles of archiving and storing information applied at the University are presented in the Records Management Policy (Taibah University 2019). Table 1 lists data storage and management services provided to educators and students at Taibah University for maintaining different types of electronic information; Figure 1 also illustrates the used services and tools.

The analysis of collected data indicates that Taibah University uses modern information technologies, primarily software and cloud services, in order to guarantee the effective document management and archiving. The used document management strategy is based on using shared and home network drives in order to ensure the arrangement, storage, and flow of all electronic materials and documents used by educators, researchers, students, and administrators in this institution. Additional components of the electronic document management system include the storage space for archiving, providing backups, and research databases (Taibah University 2019). Other components used at the University are SharePoint and OneDrive that cover stakeholders' needs regarding clouding and web-based services.

Shared network drives are accessible by different groups of specialists, and files, including organisational documents, accounting data, and information for meetings, can be accessed only by authorised users. The use of the automated system based on the secured network guarantees the quick access to data, its effective storage and management, an easy flow of information in an organisation, and the use of electronic archiving. All documents collected and stored by specialists at Taibah University are secured and have backups, but archiving for long periods of time is not guaranteed for all types of documents (Taibah University 2019). Archiving is associated with additional costs spent on storing and managing large amounts of data; therefore, the University does not provide this service for all types of documents they collect and store. The key focus is on providing regular backups for all files secured in the organisation's databases that are available for six months in order to address stakeholders' needs in archiving information.

While referring to the collected and interpreted data with reference to the previously formulated propositions, it is possible to state that Taibah University has implemented a modern and complex strategy of electronic data management that is effective for addressing the needs of educators, administrators, researchers, and students. The proposed data management services cover stakeholders' needs related to their daily operations with research- and business-related data. The second proposition was not supported as a result of conducting this case study analysis. The University has a particular system for archiving electronic documents and other types of information, but this service is provided on request, and it is not applied to all documents stored in folders and files. Therefore, it cannot be discussed as effective enough to meet all stakeholders' expectations. Still, the archiving function is partially covered by the advanced backup and restoration process adopted in the organisation. The third proposition stating that the data management system implemented at the University guarantees the secure storage of and access to data is supported with reference to the analysed data. 
Table 1. Data Management and Storage Services at Taibah University

\begin{tabular}{|c|c|c|}
\hline & Services & Function and Specifics \\
\hline 1 & $\begin{array}{l}\text { Home } \\
\text { network } \\
\text { drives }(\mathrm{H}:)\end{array}$ & 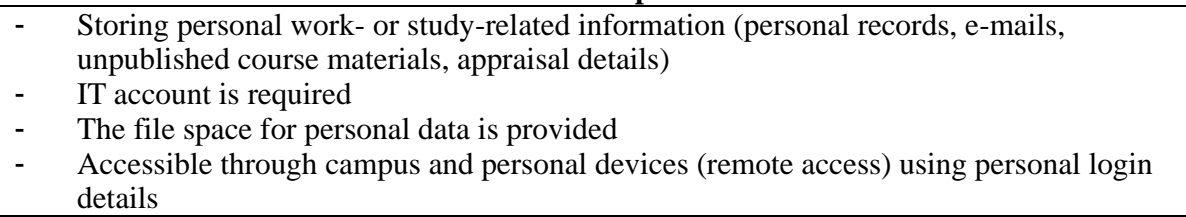 \\
\hline 2 & $\begin{array}{l}\text { Shared } \\
\text { network } \\
\text { drives }\end{array}$ & $\begin{array}{ll}\text { - } & \text { Storing business-related information (course and teaching materials, learning materials, } \\
\text { research data, administrators' files) } \\
\text { - } & \text { The network storage system } \\
\text { - } & \text { Folders are secure } \\
\text { - } & \text { Owners of shared drives are responsible for providing permission to content } \\
\text { - } & \text { Access needs to be approved through the IT Service Desk by the share owner } \\
\text { - } & \text { Additional storage can be requested }\end{array}$ \\
\hline 3 & Archiving & $\begin{array}{ll}\text { - } & \text { Space for archiving files is provided upon request } \\
\text { - } & \text { The network storage system is used for archiving documents, research materials, records } \\
\text { - } & \text { related to educators and students, e-mails, correspondence } \\
\text { - } & \text { General archiving services are provided by the University } \\
\text { - } & \text { Additional costs are covered by funders and file owners }\end{array}$ \\
\hline 4 & $\begin{array}{l}\text { Research } \\
\text { storage }\end{array}$ & $\begin{array}{ll}\text { - } & \text { Based on shared network drives } \\
\text { - } & \text { 2TB of the secure network storage is available per project } \\
\text { - } & \text { Storage of research-related data is regulated by a specific policy on security and } \\
\text { confidentiality }\end{array}$ \\
\hline 5 & $\begin{array}{l}\text { Backup and } \\
\text { restoration }\end{array}$ & $\begin{array}{ll}\text { - } & \text { Archived and stored data are regularly backed up and can be restored } \\
\text { - } & \text { The schedule for backing data up is followed } \\
\text { - } & \text { Backups are conducted nightly, weekly and monthly } \\
\text { - } & \text { Data protection is guaranteed }\end{array}$ \\
\hline 6 & SharePoint & $\begin{array}{ll}- & \text { Document management using web-based resources } \\
\text { - } & \text { Staff collaboration (research groups, educational teams) } \\
\text { - } & \text { Controlled access to secured data }\end{array}$ \\
\hline 7 & OneDrive & $\begin{array}{ll}\text { - } & \text { Storing data (1TB) using Microsoft Office } 365 \text { cloud services } \\
\text { - } & \text { IT account is required } \\
\text { - } & \text { Secured but not appropriate for storing confidential and sensitive personal data }\end{array}$ \\
\hline
\end{tabular}

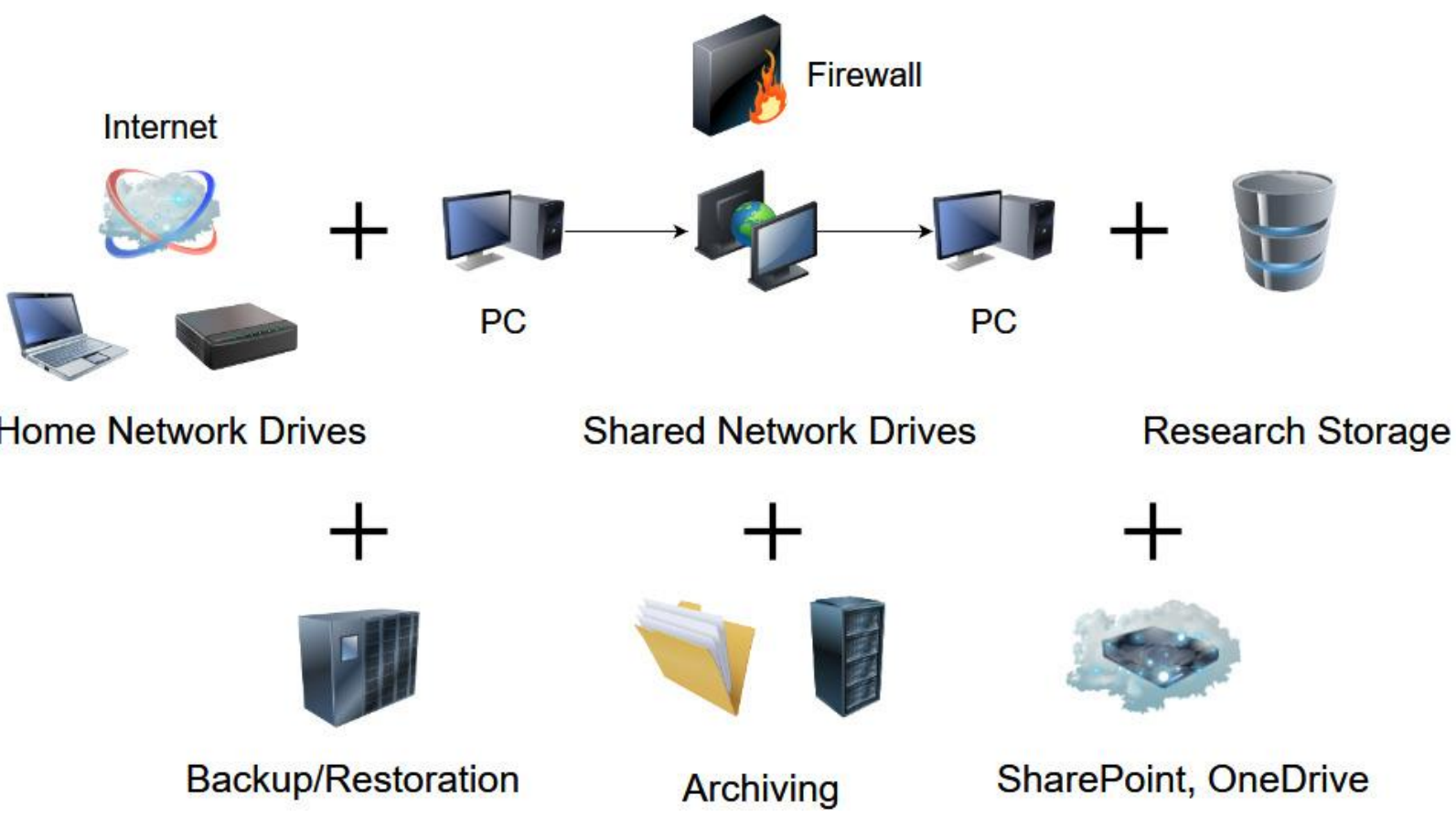

Figure 1. Data management at Taibah University 


\section{Discussion}

The findings of the case study analysis indicate that the system used at Taibah University for document management is rather efficient as it addresses the organisation's needs regarding the secure storage and archiving of data. Taibah University has developed a specific research and information management policy in order to collect and preserve data related to the activities of researchers and educators working in this institution. In spite of the fact that the strategy followed by the organisation cannot be viewed as a traditional data management system used for keeping digital information, the applied approach is effective to address this institution's goals, as it can be concluded with reference to the TTF model.

Thus, Taibah University guarantees the secure use of home and shared network drives for storing different types of data; as a result, the reliance on cloud-based systems is minimal because of the security issue. These results are in line with the conclusions by Maican and Lixandroiu (2016), according to whom, only the limited number of organisations have developed electronic data management systems, but they try to apply the elements of information management tools to meet specific organisations' requirements. Furthermore, Cristani et al. (2018) agree that clouds for storing data cannot provide users with absolute protection of their data. From this perspective, the approach followed by Taibah University to storing data when using drives and organisational networks seems to be reasonable.

Nevertheless, the analysis of an archiving process applied at the University in the context of document management indicates that Taibah University lacks an effective strategy for digital archiving. The problem is that the University needs to operate and store large amounts of data on a daily basis, but the space required for archiving researchers' files is provided only upon request. Archiving is guaranteed only for particular data required for administrators and associated with the University's functioning. However, researchers and educators can necessitate more space for storing their data for a long period of time, and additional costs are not covered by the University. According to Sabireen, Kirthica, and Sridhar (2017), archiving is important for educational institutions because of the social, cultural, and scientific significance of preserving research and educational data for different groups of users. Therefore, it is possible to state that Taibah University should improve digital archiving in the context of providing funds for storing as much data as necessary for researchers working in this institution.

Instead of expanding archiving services for the effective management of documents in the University, they use specific tools and procedures for making backup copies and the restoration of files. On the one hand, this approach allows for preserving data for several months without risks of deleting the latest and previous copies. On the other hand, backup services and restoration should be used for purposes other than archiving, and these tools cannot address the institution's need in the development of an effective archival process with the limited authorised access. Digital archiving is currently required in any organisation because the volumes of data maintained by companies will increase, and up-to-date technologies for archiving documents need to be applied to protect all data securely (Joshi \& Singh 2017; Maican \& Lixandroiu 2016). From this perspective, Taibah University can face a threat of losing or deleting files that will be required in several years because of their historical value.

\section{Conclusion}

Approaches to managing data in universities have changed significantly during recent years because of the shift to the active use of information technologies for processing and depositing data. Digitalisation has also affected the way of archiving a lot of information and provoked the development of the security question. This descriptive case study analysis has been conducted in order to determine how digital archiving and document management are organised at Taibah University for the purpose of addressing the needs of researchers, professors, administrators and students as well as to guarantee the secure storage of and access to collected data. The case study analysis of strategies applied at the University has revealed that administrators, managers, and IT specialists developed a complex strategy for storing data while using home and shared network drives, adopting SharePoint and OneDrive services, and developing procedures for research data storage and backup services. Still, this strategy has only separate elements of data management systems, and more improvements are required in order to guarantee the security of the document storage and access, as well as an easy flow of protected information in the organisation.

The focus of this research was on examining digital archiving systems applied at the University, and it has been found out that Taibah University only partially covers its stakeholders' needs regarding the creation of archives. The reason is that researchers and educators have access only to the limited space on the institution's drives to archive their data. If additional space is needed, costs are covered by researchers and funders of studies. 
Moreover, archiving services are provided automatically only in relation to a certain list of documents important for the institution's functioning. Therefore, it is possible to recommend focusing on creating additional digital document archives for Taibah University and apply the service of automatic document archiving for most files related to educators' and researchers' activities, especially with reference to keeping research data and study results.

The limitations of this research are associated with the qualitative methodology and the selected descriptive type of a case study. This method was chosen as most appropriate to address the set research question, but it is also possible to predict achieving a more in-depth understanding of the problem with reference to conducting interviews with academicians and IT specialists working at Taibah University. The reference to these employees' experience will contribute to retrieving more details regarding document management and archiving in the selected educational institution.

In spite of the limitations identified for this study, it is important to accentuate strengths of this research and its contribution to theory and practice of information management in organisations. As it is revealed with reference to the study, data management systems need to address the needs of organisations regarding their specific activities. Furthermore, provided web-based resources and software should have enough space in order to securely store all the business-related data. The situation when archiving in an organisation has certain weaknesses can lead to the inadequate storage of important historical and research data. Therefore, the results of this research emphasise the importance of selecting most advanced data management approaches to meet corporate requirements and pay attention to digital archiving of data while guaranteeing the security of information.

\section{References}

Cristani, M., Bertolaso, A., Scannapieco, S., \& Tomazzoli, C. (2018). Future paradigms of automated processing of business documents. International Journal of Information Management, 40, 67-75. https://doi.org/10.1016/j.ijinfomgt.2018.01.010

Howard, M. C., \& Rose, J. C. (2018). Refining and extending task-technology fit theory: creation of two task-technology fit scales and empirical clarification of the construct. Information \& Management, 1, 1-64.

Joshi, C., \& Singh, U. K. (2017). Information security risks management framework-a step towards mitigating security risks in university network. Journal of Information Security and Applications, 35, 128-137. https://doi.org/10.1016/j.jisa.2017.06.006

Koopman, M. M., \& De Jager, K. (2016). Archiving South African digital research data: how ready are we? South African Journal of Science, 112(7-8), 1-7. https://doi.org/10.17159/sajs.2016/20150316

Maican, C., \& Lixandroiu, R. (2016). A system architecture based on open source enterprise content management systems for supporting educational institutions. International Journal of Information Management, 36(2), 207-214. https://doi.org/10.1016/j.ijinfomgt.2015.11.003

Renaut, S., Budden, A. E., Gravel, D., Poisot, T., \& Peres-Neto, P. (2018). Management, archiving, and sharing for biologists and the role of research institutions in the technology-oriented age. BioScience, 68(6), 400-411. https://doi.org/10.1093/biosci/biy038

Sabireen, H., Kirthica, S., \& Sridhar, R. (2017). Secure data archiving using enhanced data retention policies. Paper presented at International Conference on Data Science Analytics and Applications, DASAA, Singapore (pp. 139-152). https://doi.org/10.1007/978-981-10-8603-8_12

Soomro, Z. A., Shah, M. H., \& Ahmed, J. (2016). Information security management needs more holistic approach: a literature review. International Journal of Information Management, 36(2), 215-225. https://doi.org/10.1016/j.ijinfomgt.2015.11.009

Srivastava, S., \& Misra, R. (2017). Archiving ERP data to enhance operational effectiveness: the case of Dolphin. International Journal of Information Technology and Management, 16(2), 162-172. https://doi.org/10.1504/IJITM.2017.083866

Taibah University. (2019). Data storage and archiving.

Van Loon, J. E., Akers, K. G., Hudson, C., \& Sarkozy, A. (2017). Quality evaluation of data management plans at a research university. IFLA Journal, 43(1), 98-104. https://doi.org/10.1177/0340035216682041

Wu, B., \& Chen, X. (2017). Continuance intention to use MOOCs: integrating the technology acceptance model (TAM) and task technology fit (TTF) model. Computers in Human Behavior, 67, 221-232. 
https://doi.org/10.1016/j.chb.2016.10.028

Yin, R. K. (2017). Case study research and applications: Design and methods (6th ed.). SAGE Publications, Los Angeles, CA.

\section{Copyrights}

Copyright for this article is retained by the author(s), with first publication rights granted to the journal.

This is an open-access article distributed under the terms and conditions of the Creative Commons Attribution license (http://creativecommons.org/licenses/by/4.0/). 